\title{
La movilización de la lectura en España durante la I Guerra Mundial
}

\author{
Alfonso GonZÁLEZ QueSADA \\ Universidad Autónoma de Barcelona \\ Alfons.gonzalez@uab.cat
}

Recibido: 1 de junio de 2014

Aceptado: 9 de septiembre de 2014

\section{Resumen}

El artículo identifica y describe las iniciativas que se pusieron en marcha en España para proporcionar lectura a los combatientes, prisioneros y heridos durante la Primera Guerra Mundial. Se dedica una atención especial a la labor desarrollada por las organizaciones que atendieron al contingente de voluntarios españoles que lucharon en el ejército francés. La documentación estudiada permite hacer una estimación de la cantidad de libros y publicaciones que cada iniciativa distribuyó. Se señalan también los objetivos que pretendían conseguir con la lectura enviada, así como la significación que ésta tuvo entre sus destinatarios.

Palabras clave: I Guerra Mundial; libros; prensa; soldados; España.

\section{The Reading Mobilization in Spain during the First World War}

\begin{abstract}
This article identifies and describes the initiatives launched in Spain to provide reading material to combatants, prisoners and the wounded during First World War. Special attention is paid to the work of organizations who attended the Spanish volunteers who fought in the French army. The study provides an estimate of the number of books and publications distributed by each initiative. The aims that said initiatives were trying to obtain with reading sent are also indicated, as well as the significance that reading had among its recipients.
\end{abstract}

Key words: First World War; books; press; soldiers; Spain.

\section{Referencia normalizada}

González Quesada, A. (2014). La movilización de la lectura en España durante la Primera Guerra Mundial. Historia y Comunicación Social. Vol 19, páginas 15-31.

Sumario: 1. Introducción. 2. Objetivos y fuentes de consulta. 3. Iniciativas para el envío de lectura a heridos y prisioneros de guerra. 4. Iniciativas para el envío de lectura a los voluntarios españoles. 4.1 ¿Cuántos libros y periódicos recibieron los voluntarios? 4.2. ¿Qué prensa leyeron los voluntarios? 4.3. ¿Qué funciones cumplió la prensa entre los voluntarios? 4.3.1. La prensa, medio de distracción. 4.3.2. La prensa, fuente de información. 4.3.3. Leer para compartir ideales. 4.3.4. La prensa, instrumento de apoyo moral. 4.3.5. La prensa, un bien a compartir. 4.3.6. La prensa, tribuna para el narcisismo, la ayuda y la polémica. 4.3.7. El poder evocador de la prensa. 5. La biblioteca del foyer de Vallbonne. 6. ¿Qué libros leyeron los voluntarios? 7. Conclusiones. 8. Referencias bibliográficas. 


\section{Introducción}

Pocos días después de estallar la guerra en Europa, el gobierno de Eduardo Dato se apresuró a declarar la neutralidad de España. Una decisión que ahondó la división política del país, escindida desde entonces entre aliadófilos y germanófilos. Los sectores liberales y progresistas, identificados con los principios del parlamentarismo, se alinearon con Francia e Inglaterra; mientras que los grupos más conservadores, se inclinaron por los imperios centrales al entender que defendían valores tradicionales como el orden y la disciplina.

Circunstancias de diversa índole empujaron a un reducido número de españoles, en su mayoría catalanes, a combatir como voluntarios en el Regimiento de Marcha de la Legión Extranjera del ejército francés. Algunos rotativos barceloneses exaltaron la contribución a la guerra de aquel contingente, con el propósito de mostrar que Cataluña luchaba al lado de la Entente. Aquella misma prensa, proclive a resaltar el fenómeno de los voluntarios, puso en marcha a finales de 1915 distintas iniciativas para proporcionarles auxilio material. La Nació emprendió una campaña de apadrinamiento de soldados, mientras que Iberia abrió una suscripción para enviar al frente ropa, tabaco y alimentos. Más adelante, este mismo semanario recomendaría que en los envíos "aún podría añadirse algo que no falta nunca en los paquetes franceses: (...) algo para leer, libros y periódicos" ". Por primera vez se hacía explícita la voluntad de hacer llegar material de lectura a los voluntarios, cuando en esas fechas aquélla era ya una práctica compartida e institucionalizada por los principales países en guerra.

Conscientes de la necesidad del sostenimiento anímico de las tropas, y de acuerdo con su capacidad organizativa y recursos disponibles, las potencias beligerantes diseñaron actividades para ocupar el tiempo libre de los soldados y mitigar la angustia que imponía la vida en las trincheras. Una de ellas fue el establecimiento de servicios de lectura, de manera que libros, diarios y revistas llegaron a los más diversos escenarios del conflicto. Alemania creó un excelente servicio, apoyado por las feldbuchhandlung, librerías para soldados, instaladas en localidades próximas a las líneas del frente (Natter, 1999: 122-173).

No menos excelentes fueron los servicios británico y americano para sus tropas expedicionarias. En Estados Unidos, el Library War Service, liderado por bibliotecarios, aunó los esfuerzos de todas las entidades que trabajaban para conseguir de la ciudadanía recursos con los que proporcionar lectura a sus soldados (Young, 1981).

En Francia, el acceso a la lectura se canalizó a través de los foyers du soldat, establecimientos repartidos por las zonas cercanas a los frentes y en las principales ciudades del país, donde además de leer, charlar y tomar bebidas no alcohólicas, los poilus podían disfrutar de música y proyecciones cinematográficas. Aunque al principio las autoridades francesas fueron reticentes a la extensión de los foyers, el desánimo de las tropas, que no vislumbraban el final del conflicto, y los motines de 1917 persuadieron de la necesidad de mejorar las condiciones de vida de los soldados. A tal fin 
contribuyó la distribución, entre más de un millar de foyers, de pequeñas bibliotecas, rigurosamente seleccionadas bajo supervisión militar (Muller, 2000).

\section{Objetivos y fuentes de consulta}

El contacto de los soldados españoles con la lectura no se limitó a los foyers. Desde España se les envió prensa y libros con cierta regularidad. Además, conviene señalar que la movilización de la lectura en España no se ocupó solo de los voluntarios que combatían en el ejército francés; heridos y prisioneros también recibieron libros y otras publicaciones con que aliviar el trance que el conflicto les había deparado. Este trabajo explora tales iniciativas y, en concreto, pretende identificar las entidades que desde España enviaron libros y prensa a los combatientes, así como sus objetivos; determinar el perfil del material enviado; cuantificar su número y conocer, en la medida de lo posible, la significación que su lectura tuvo entre los destinatarios.

Para realizar la investigación se han consultado fuentes archivísticas, hemerográficas y bibliográficas. El Archivo General de Palacio de Madrid conserva el fondo de la Oficina Pro Cautivos, la iniciativa de Alfonso XIII para auxiliar a los prisioneros de ambos bandos. Tal y como atestigua la documentación, varias decenas de miles de libros se enviaron a campos de internamiento alemanes y franceses. En el Arxiu Nacional de Catalunya, el fondo Solé i Pla contiene la correspondencia que el presidente del Comitè de Germanor amb els Voluntaris Catalans mantuvo con los combatientes, así como el libro de cuentas del Comitè, donde se registró la compra de libros y prensa para los soldados y su distribución. Sin llegar a la minuciosidad de la documentación del Comitè, la memoria del Patronato de Voluntarios Españoles ofrece datos sobre el volumen y perfil del material de lectura que movilizó. La prensa aliadófila ha sido una fuente valiosa para conocer las iniciativas que hicieron llegar lectura a los combatientes. Periódicos de trinchera, así como epistolarios y relatos publicados al poco de finalizar el conflicto por el Patronato de Voluntarios Españoles también han contribuido a desvelar la significación que la lectura tuvo para los soldados.

\section{Iniciativas para el envío de lectura a heridos y prisioneros de guerra}

En septiembre de 1915, Pere Coromines, líder del nacionalismo catalán republicano y, a la sazón, director de El Poble Català, publicó en sus páginas 'Per l'amor de França', un panegírico sobre la cultura francesa. La obra se enmarcaba en la campaña del diario en favor de la causa aliada. Posteriormente, Coromines editó el mismo ensayo en forma de opúsculo y los beneficios de su venta fueron la primera aportación para la campaña 'Pels ferits francesos', iniciada desde aquel diario a principios de 1916, y dada a conocer por otras publicaciones. En pocos meses consiguió 
reunir fondos para adquirir cerca de 800 volúmenes, que destinó a los soldados franceses convalecientes en hospitales militares. La selección incluyó fundamentalmente autores galos, clásicos y contemporáneos, sin descuidar las principales figuras de la literatura universal, con la excepción, nada casual, de escritores de origen germánico. Para Coromines, el acatamiento de la neutralidad no le podía obligar a ser imparcial; por eso, más allá de la significación humanitaria de su iniciativa, ésta tuvo una clara implicación política.

De mayor envergadura, y ajena a cualquier orientación política, fue la actividad de la Oficina Pro Cautivos. Desde finales de 1915, la embajada española en Berlín comenzó a recibir peticiones de libros y revistas en español por parte de franceses internados en Alemania. No buscaban solo una fuente de distracción, sino, sobre todo, apoyo material para las clases de español que muchos de ellos impartían en los centros de reclusión. Inicialmente la embajada no pudo satisfacer aquellas demandas hasta que la Oficina Pro Cautivos, establecida por Alfonso XIII para atender las solicitudes de información sobre prisioneros y desaparecidos de ambos bandos, remitió alrededor de 40.000 volúmenes donados en su mayoría por la Asociación de la Librería Española. El secretario particular de Alfonso XIII destacó la doble significación de aquellos envíos:

Permitirá no solamente realizar una obra humanitaria (...) sino también una obra patriótica cual es la de difundir el conocimiento de nuestro idioma y de nuestros mejores autores presentes y pasados, en circunstancias tales que harán difícil, si no imposible el olvido de uno y de otros ${ }^{2}$.

\section{Iniciativas para el envío de lectura a los voluntarios españoles}

Hubo dos organizaciones dedicadas a la asistencia de los combatientes españoles que lucharon con el ejército francés: el Comitè de Germanor amb els Voluntaris Catalans y el Patronato de Voluntarios Españoles. Aunque ambas entidades enviaron, de forma más o menos regular, dinero, alimentos, ropa y también lectura, el contenido político de la labor de cada una fue bien distinto.

La creación en febrero de 1916 del Comitè aglutinó las tentativas de ayuda a los voluntarios que prensa y partidos políticos aliadófilos habían emprendido tiempo atrás de manera dispersa. El Comitè pretendió hacer de la participación de catalanes en la guerra, una baza política en pro del reconocimiento de Cataluña en el nuevo orden internacional que se configuraría tras una victoria aliada. Y una parte de la lectura que envió buscó trasladar a los combatientes aquel anhelo. El presidente y alma mater del Comitè fue el doctor Solé i Pla, quien canalizaba desde Barcelona todas las actividades relacionadas con los voluntarios.

A inicios de 1918, se dieron los primeros pasos para constituir un 'comité de hermandad madrileño', tal y como lo definió su futuro secretario, José Subirá. Éste combinaba la crítica musical con la labor propagandística a favor de los españoles 
que luchaban en las filas del ejército francés. Quiso imitar la iniciativa de Solé i Pla y para ello le pidió consejo, así como la relación de voluntarios no catalanes de que disponía. El 9 de mayo de 1918, se creó el Patronato de Voluntarios Españoles, con objetivos idénticos a los del Comitè, en cuanto a la ayuda material a los soldados, pero sin compartir su trasfondo político.

\section{1 ¿Cuántos libros y periódicos recibieron los voluntarios?}

Es imposible conocer con exactitud el número de libros, diarios y revistas que recibieron los soldados españoles. Apenas existen datos de los envíos que hicieron partidos políticos, escritores y ciudadanos particulares comprometidos con la causa que representaban los voluntarios, por lo que las cifras que se ofrecen a continuación se fundamentan solo en la documentación del Comitè ${ }^{3}$ y el Patronato ${ }^{4}$, y son una estimación de lo suministrado por ambas organizaciones. De esta manera, según recoge su memoria de actividad, el Patronato llegó a distribuir cerca de 700 libros; mientras que el registro de Solé i Pla, aunque solo documente el envío de 579 ejemplares, los gastos por la compra de libros y sellos para su expedición permiten suponer que el número de libros distribuidos por el Comitè se situaría alrededor de los 2.000 .

El primer envío de prensa del Comitè del que se tiene constancia tuvo lugar en mayo de 1916 e incluía 120 paquetes de periódicos. Las cifras oscilaron mes a mes. En octubre de aquel año, el número de paquetes se redujo a 62, mientras que entre diciembre de 1917 y enero de 1918 superó los 500. Los envíos se mantuvieron hasta febrero de 1919, tres meses después del armisticio, de manera que a lo largo de los 34 meses que van desde mayo de 1916 hasta febrero de 1919 el Comitè remitió alrededor de 4.200 paquetes.

Hablar de 'paquete de periódicos' supone emplear una unidad de medida muy imprecisa. El registro de Solé i Pla da pocas pistas para saber cuántos ejemplares solía contener un paquete. Sólo en una ocasión apunta el número de diarios de dos paquetes expedidos en la misma fecha: cada uno incluía ocho ejemplares. Quizá la excepcionalidad de la cantidad justifique que se trate de la única anotación sobre el contenido de un envío. La correspondencia de los voluntarios arroja algo más de luz sobre este punto.

Era frecuente que en sus cartas agradecieran los envíos y los describieran a modo de acuse de recibo. Gracias a esa información, se conoce que los paquetes normalmente incluían de tres a cinco ejemplares. Si de media un paquete estaba formado por cuatro periódicos, el número aproximado de ejemplares que el Comitè destinó a los voluntarios superaría los 16.000 . Esta estimación parece del todo verosímil atendiendo al registro de compra de publicaciones. Aunque no haya prácticamente datos sobre las compras efectuadas a lo largo de 1916, el cómputo de las realizadas entre diciembre de aquel año y febrero de 1919 indica que se adquirieron cerca de 13.000. Es lícito aventurar que, si a esta cifra se añade la correspondiente al periodo sobre el que no hay datos de compras, pero sí de envíos, el total de publicaciones que el Comitè remitió a los voluntarios rondaría o superaría las 16.000. Y si, además, se 
tiene en cuenta que el Patronato proporcionó 'cientos de periódicos y revistas', la cantidad final se aproximaría a las 17.000.

Al lado de la magnitud de los servicios de lectura de la mayoría de países en guerra, las cifras expuestas son insignificantes, pero muy razonables si se atiende a la dimensión del contingente que combatió: alrededor de 2.000 hombres (Martínez i Fiol, 1991: 116). Tampoco hay que olvidar que las iniciativas descritas nunca contaron con apoyo oficial alguno y que, al margen de sus objetivos políticos, fueron el resultado del altruismo y la generosidad de un círculo muy reducido de personas, persuadidas por la significación atribuida a la presencia de los voluntarios en el conflicto.

Como colofón a este apartado conviene resaltar otra cuestión. Aunque fuera más económico comprar y enviar prensa que libros, las motivaciones económicas no son las únicas que explican la diferencia notable entre el número de libros y publicaciones periódicas distribuidas entre los soldados. También se debe considerar la significación que ambos materiales de lectura tuvieron y los objetivos que debían cumplir para quienes los remitieron desde la Península.

\section{2. ¿Qué prensa leyeron los voluntarios?}

Toda la prensa destinada a los voluntarios fue aliadófila. El Patronato solía incluir en sus envíos un ejemplar de la revista Esfera, y durante la Navidad de 1918, junto a otros regalos, hizo llegar números de Nuevo Mundo y Mundo Gráfico. Por su parte, el Comitè conformó, entre la prensa catalanista republicana, un canon de títulos compuesto principalmente por los semanarios Iberia, La Nació, La Campana de Gràcia y L'Esquella de la Torratxa y el diario El Poble Català. La selección de estas cabeceras obedeció tanto a su proximidad ideológica con los del Comitè, como a la atención que dedicaban a los voluntarios. Iberia incluía 'Els catalans a la guerra', una sección que daba noticia de sus acciones, mientras que El Poble Català publicaba las crónicas del legionario Frederic Pujolà y los artículos, no exentos de propaganda, que con cierta regularidad firmaba bajo pseudónimo el mismo Solé i Pla.

El registro del Comitè demuestra que Iberia fue la publicación de la que se adquirió mayor número de ejemplares, superando los 4.000. Iberia había surgido meses después del inicio de la guerra con el objetivo de defender la causa aliada y crear desde Cataluña una corriente de opinión favorable a una profunda reforma del Estado que incluyera la desaparición de la monarquía tras el final del conflicto mundial.

Algo por debajo de la cifra de Iberia se situaron las satíricas La Campana de Gràcia y L'Esquella de la Torratxa, con cerca de 3.000 cada una. No hay datos sobre el volumen de compras de El Poble Català, ni de La Nació, este último portavoz de la Unió Catalanista, partido que presidió Solé i Pla. A pesar de la ausencia de datos, la estrecha relación de Solé i Pla con ambos periódicos se tradujo en su inclusión habitual en los envíos. Ambas publicaciones fueron muy populares y queridas por los soldados. No en vano La Nació fue considerada como el órgano oficial del contingente catalán hasta su desaparición, en enero de 1917. A modo de ejemplo de lo que se acaba de apuntar baste la siguiente muestra de agradecimiento del soldado Miquel 
Freixes, dedicando unos versos al periódico: "Yo saludo a La Nación / y a sus dignos directores / porque son todos señores / de muy noble corazón. / Siempre dicen la razón / cuando escriben de la guerra"5.

Otros títulos también llegaron a los combatientes. Así, de Il·lustració Catalana se compraron unos 400 ejemplares. Cifras más discretas alcanzaron La Publicidad, El Diluvio y Las Noticias. En marzo de 1918, apareció el Butlletí del Comitè de Germanor amb els Voluntaris Catalans. Parte de su objetivo fue cubrir el vacío dejado por La Nació. Por esta razón se dirigía tanto a los miembros y simpatizantes del Comitè, a quienes daba noticia de sus actividades e informaba de las gestas de los voluntarios, como a los propios combatientes. Si el Butlletí fue el nexo entre los voluntarios y los sectores de la sociedad catalana persuadidos por la significación política de su presencia en el conflicto, Trinxera Catalana surgió con la intención de establecer un vínculo ideológico entre los miembros de aquel contingente.

La prensa despertaba un enorme interés entre los soldados. Era el único medio que les daba cuenta del curso general del conflicto. Sin embargo, a menudo echaban en falta el reflejo de su experiencia particular, la referencia a sus penalidades y sacrificios. El olvido de lo propio cotidiano por la prensa convencional provocaba frustración y, en no pocas ocasiones, condujo a su menosprecio. En ese contexto surgieron publicaciones exclusivas para soldados. En unos casos, sus responsables fueron las autoridades militares; en otros, aparecieron por iniciativa de los mismos combatientes. Si las primeras buscaron fortalecer la moral y la disciplina y fueron ampliamente distribuidas entre la tropa; las segundas, conocidas como periódicos de trinchera, retrataron la vida cotidiana en el frente sin renunciar al humor y la ironía. Hablar de la experiencia de la guerra, de anhelos y temores comunes, desde la proximidad entre testimonio y lector, entre lo vivido y lo leído, y hacerlo a partir de referentes compartidos explican el atractivo de los periódicos de trinchera y su proliferación en todos los ejércitos (Nelson, 2010).

El reducido contingente de voluntarios catalanes también tuvo su publicación. Trinxera Catalana estableció un vínculo entre los combatientes más activos cercanos al nacionalismo radical, y actuó como portavoz de sus expectativas sobre las repercusiones que una victoria aliada pudiera tener en el reconocimiento internacional de Cataluña. La idea de la publicación partió del soldado Camil Campanyà. Cuando estalló la guerra era presidente de Joventut Catalanista, la cantera de Unió Catalanista. Años antes, había emigrado a Cuba, donde entró en contacto con la diáspora del independentismo catalán. Campanyà había expuesto sus credenciales políticas a Solé i Pla, antes de que a finales de febrero de 1916 le confiara su proyecto y le solicitara colaboración para el primer número con algún texto "enaltint França i la seva causa $i$, si fos posible, escrit en francés"'. Con aquel gesto, Campanyà esperaba ganar adhesiones entre las autoridades militares y sus camaradas franceses. También pensaba incluir algún poema de Guimerà dedicado a los voluntarios, o de otro poeta de renombre. 
Un mes después, Emili March, que secundaba a Campanyà en el proyecto, escribió a Solé i Pla revelándole que el título del futuro periódico sería Trinxera Catalana. En abril, Campanyà confiaba en que apareciera quincenalmente a partir de finales de aquel mes. En junio, Iberia se hizo eco de la iniciativa y declaró su apoyo para que se pudiera "satisfacer la aspiración declarada por los que tan generosamente luchan de publicar un periódico redactado en las trincheras", y añadía que en la nueva publicación "colaborarán muchos de nuestros escritores, que así pondrán en el corazón de los voluntarios un recuerdo y un aliento de la patria, pero, claro está; la mayor parte del periódico estará hecho de los voluntarios, exclusivamente"7.

La muerte de Campanyà en la ofensiva del Somme retrasó la aparición de Trinxera Catalana hasta finales de 1916, y ya desde el primer número las dificultades para su continuidad fueron muchas. La pretendida periodicidad nunca se cumplió, y transcurrieron dos años hasta que apareció el segundo número. Los dos últimos lo hicieron una vez firmado el armisticio; el de noviembre de 1918, con una tirada de 300 ejemplares y el de diciembre, alcanzando el millar.

4.3. ¿Qué funciones cumplió la prensa entre los voluntarios?

La mejor manera de dar respuesta a esta cuestión es acudir al testimonio de los combatientes para descubrir los distintos usos y significaciones que la prensa tuvo para ellos.

\subsubsection{La prensa, medio de distracción}

El afán por leer acompañó a los combatientes desde el inicio del conflicto. Antes incluso de que existieran el Comitè y el Patronato, los soldados pedían a familiares y amigos lecturas con las que hacer más llevadera la vida en el frente. Un ejemplo es el de Angel Nat. En marzo de 1915 escribió a sus padres para conseguir algún ejemplar de Papitu, un semanario satírico muy popular, porque "passem moltes hores sense fer res"s.

Tampoco Solé i Pla tuvo que esforzarse para despertar el interés por leer entre los voluntarios. Cuando entraba en contacto con alguno de ellos para conocer qué necesitaban, lo primero y, en algunos casos, lo único que solicitaban era algo de lectura, porque, como lamentaba Ángel Martínez, "l'única distracció que tenim és el canó i la metralladora". Lo mismo sucedía cuando los propios voluntarios se presentaban a Solé i Pla. Ese es el caso de Ernest Casalta, quien le explicaba que "trobant-me a Vallbonne en aquests moments, el faig coneixedor del meu estat, perquè si li plau, m'envil̈ periòdics" 10 .

Las muestras de alegría y agradecimiento fueron habituales al recibir cualquier tipo de publicación. Lógicamente, las incidencias en los envíos eran fuente de desazón o incertidumbre, cuando no de sorpresa, como la del soldado que preguntó alarmado a Solé i Pla si La Nació había dejado de publicarse, al descubrir que su paquete solo contenía ejemplares de El Poble Català, cuando solía recibir de ambos periódicos. 
Otros culpaban de los retrasos o las pérdidas a la censura militar, que ciertamente llegó a mutilar ejemplares, pero hubo actitudes más desenfadadas, como la de Pere Llensa, quien comentó a Solé i Pla que "los diaris que amb l'altra carta diu que nos ha enviat no los hem rebut encara; això no tingui por, no's perdran, si fossin llonganisses es perdrien"

\subsubsection{La prensa, fuente de información}

El afán por saber se podía satisfacer con la prensa francesa que los voluntarios encontraban en el frente o en los foyers. A través de ella también conocían ocasionalmente la repercusión de las acciones de su regimiento. Cuando esto sucedía, no dudaban en comentarlo en sus cartas e incluir recortes de prensa. Pero para quienes dominaban el francés, aquellos diarios sabían a poco, porque apenas dedicaban atención a la convulsa situación que atravesaba España, aunque, si se hace caso del comentario de Ferriol Palé, tampoco parecían hacerlo los diarios madrileños que encontró a su paso por París "perquè només parlen de toros" 12 .

Fue gracias a las publicaciones que recibían de Madrid o Barcelona que los voluntarios superaban la "crisi de noves en lo que a Espanya es refereix"13. Así podían seguir de cerca la actualidad del país y hacerse eco de ella en su correspondencia: desde las tensiones que condujeron al conato revolucionario de 1917, hasta la trágica muerte de Enrique Granados. Pero por encima de todo, entre los voluntarios existía el deseo común de saber qué se decía de ellos y, en especial, qué decían los periódicos que compartían la causa por la que luchaban. La neutralidad había transformado la prensa en el principal campo de batalla ideológico donde se dirimía el enfrentamiento que dividía la sociedad española. No es extraño entonces que, ante opiniones y actitudes germanófilas, se elogiase desde el frente la beligerancia de publicaciones como Iberia, que respondía con "virilitat i energia com si realment fos un canó de 400 dels que tenim aquí" 14 .

\subsubsection{Leer para compartir ideales}

Los soldados agradecían el compromiso y apoyo de la prensa proaliada. Eran conscientes de que luchaban en el mismo bando, aunque que con armas diferentes. Pocos testimonios reflejaron tan bien esa conciencia como la de Jaume Pou:

No tothom serveix per anar al front, és veritat, però n'hi ha que no podran passar una nit llarga i freda plena d'angoixa amb lo fusell o la bomba a la mà, però en canvi, aqueixos són capaços per tenir una ploma a la mà i escriure paraules encoratjadores per aquells que lluiten a la trinxera, aqueixos que no són bons per anar al front, i que escriuen i parlen tan bé, algun dia quan l'hora de la justícia arribi, ells amb les seves eloqüents paraules sabran reclamar i defensar la causa que tots, uns i altres defensem: los uns amb lo fusell i los altres amb la ploma, doncs, aquests són uns herois, tant o més que nosaltres ${ }^{15}$ 


\subsubsection{La prensa, instrumento de apoyo moral}

A pesar de las diferencias evidentes en la prensa aliadófila, los combatientes hallaron en sus páginas los tópicos del idealismo que los había empujado a luchar. Estos diarios que "escriuen les nostres idees" 16 , como los definía Enric García desde un campamento argelino o, a través de los que Jaume Pou conocía "la marxa de les nostres idees i aspiracions" ${ }^{17}$ representaron un enorme refuerzo moral para los soldados. Confiaban que estaban librando la última guerra del género humano, y que la victoria conduciría a un nuevo orden, basado en la justicia, la democracia y la libertad. Pero también es cierto que el tipo, el alcance y las repercusiones de las libertades que vislumbraban no eran idénticos para todos los voluntarios. Hombres como Francesc Bernabé confiaban en el triunfo de la justicia social, y por esa razón su moral crecía "al ver que a la vez que nosotros combatimos en el frente, nuestros hombres políticos estudian y trabajan para la libertad y tranquilidad del porvenir de la clase obrera"18.

Entre los combatientes catalanes los había que se inclinaban por un ideal expresado en términos de reconocimiento de su identidad nacional. En buena medida, las acciones del Comitè perseguían reforzar la esperanza de que, una vez acabada la guerra, el sacrificio de los voluntarios contribuyera decisivamente a solucionar la denominada 'cuestión catalana'. La prensa republicana barcelonesa avivó esa esperanza a lo largo del conflicto, aunque con intermitencias.

\subsubsection{La prensa, un bien a compartir}

Como sucedía con otros pequeños placeres materiales en las trincheras, la lectura se socializaba. Libros, revistas y periódicos circularon de mano en mano para luego conversar o discutir sobre ellos. Compartirlos fue un gesto de camaradería, como el de Josep Torelló. Él era quien redactaba las cartas del soldado Víctor Sendra, y quien se las leía, porque su compañero no sabía, y como eran amigos, en contrapartida por su ayuda "tots els periòdics que li han enviat me'ls ha dat"19, confesaba Josep. Jaume Pallarès, internado en un hospital de Angers, repartía sus periódicos entre los heridos que convalecían con él y relataba a Solé i Pla cómo disfrutaban leyéndolos. Muchos más fueron los soldados que hojearon los que recibía Antonio Gómez, porque una vez leídos por todos los voluntarios que había en su compañía, los enviaba a otra, para que así pudieran hacerlo todos los soldados del regimiento.

\subsubsection{La prensa, tribuna para el narcisismo, la ayuda y la polémica}

Si la prensa ilustrada atraía por el poder de la imagen, ese atractivo se multiplicaba cuando la imagen era la de uno mismo. Algunos combatientes firmaban crónicas o enviaban retratos que acompañaban la reseña de sus hazañas, haciendo de la prensa un aparador de vivencias, aventuras y gestas guerreras. Un acto de narcisismo comprensible que continuaba cuando los voluntarios querían conseguir el ejemplar en el que había aparecido su fotografía. Por eso, Enric García escribía a Solé i Pla: "M'agradaria molt que fes tots els possibles per trobar-lo car ell serà l'únic record 
de la Legió Estrangera que podria guardar"20. En otras ocasiones, Solé i Pla recibía la petición de soldados que deseaban publicar su fotografía con la esperanza de ser reconocidos por familiares o amigos y recibir de ellos algo de ayuda.

Los combatientes leían atentamente todo lo que se decía de ellos. Las crónicas les permitían saber cuál había sido la suerte de otros compañeros. Comentaban y valoraban positivamente los artículos que se les dedicaban, pero también censuraban los olvidos de la prensa, las inexactitudes que podían derivar en polémicas cuando afectaban a lo personal. Joan Bastús se quejaba de que La Nació hubiera informado erróneamente del número de citaciones obtenidas por el soldado Josep Curto, que solo tenía una, como él. No solo censuraba el afán de notoriedad de Curto, que era quien había escrito al diario, sino la falta de rigor del propio medio. Un mes después Bastús comentaría con ironía a Solé i Pla que La Nació hacía bien de no hablar de la guerra, porque "cada dia los abusos serien més grans i allavors lo diari acabaría per perdre la reputació" 21 .

\subsubsection{El poder evocador de la prensa}

Leer en la propia lengua tuvo un poder evocador inmenso para quienes habían dejado su patria y arriesgaban la vida en tierra ajena. Aunque algunos de ellos vivieran fuera de España mucho antes del estallido de la guerra, el sentimiento de nostalgia afloraba cuando caía en sus manos un diario en su lengua. Por esa razón, Alfred Barceló pedía a Solé i Pla "si no té inconvenient d'enviar-nos alguns diaris catalans per a poder passar uns moments distrets i recordar els temps que passàvem en aqueixa terra catalana"22.

Un voluntario convaleciente en un hospital agradecía al Patronato los diarios recibidos “(...) porque para mí es una dicha poder leer algo que, sin ser mistificado, como pasa a menudo en las revistas extranjeras, me hable de mi querida España. Al ver ahora aquellas páginas que tanto me entusiasman, siento rejuvenecerme y soy más español que nunca"23. En la misma línea se expresaba Joan Bastús en agradecimiento por las "fulles de la meva estimada terra, que m'han fet reviure los dolços records que d'ella tenia"24. El soldado Serrat i Casas fue más sentido en su agradecimiento,

no podeu imaginar-vos amb l'alegria que els hem llegit, malgrat haver-los llegits i rellegits els guardo com si dintre dels articles que encaixen s'hi trobessin bocins de totes aqueixes coses tan grates que tot home allunyat de sa pàtria estima per damunt de totes les riqueses i plaers del món ${ }^{25}$.

\section{La biblioteca del foyer de Vallbonne}

En el campamento de Vallbonne, cerca de Lyon, recibían instrucción los voluntarios antes de ser destinados al frente. El campamento contaba con un foyer, donde los soldados, cuando no tenían servicio, se podían reunir para charlar, comer y beber, siempre que no fuese alcohol. El foyer ofrecía además papel timbrado, plumas y tinta 
y una biblioteca, que fue punto de encuentro de los voluntarios catalanes. Allí tuvieron lugar las reuniones del centro excursionista y de la coral que crearon. Para aquellos hombres la biblioteca se convirtió también, en palabras de Solé i Pla, en “(...) ateneu on se donaven conferències serioses, o que volien ésser-ho i amb la intenció prou n'hi havia, on se feien controvèrsies a voltes llargues que duraven hores (...)"26.

Aquellas controversias exigían argumentos y éstos solo se podían obtener mediante la lectura, pero la biblioteca del foyer no contaba con el material idóneo, por eso hubo voluntarios que pidieron al Comitè libros de historia, porque algunos de ellos "se trobaven a llavors en falla per sa poca cultura histórica. A estudi no se'ls havia ensenyat res més que les beceroles i les quatre regles"27. Aquellos envíos fueron nutriendo una pequeña colección donde no faltaron las obras de Rovira i Virgili o d'Eugeni Xammar, ni la prensa que recogía los discursos de Martí i Julià y de otros catalanistas republicanos comprometidos con la causa aliada. Aquel material, más allá de azuzar las discusiones históricas y políticas, ayudó a consolidar el ideario común de un reducido número de combatientes, que entendieron su participación de la guerra como la punta de lanza de una futura reivindicación catalana en el concierto internacional.

\section{6. ¿Qué libros leyeron los voluntarios?}

Como se comentó a la hora de referirse a la prensa, las fuentes disponibles no ofrecen información exhaustiva ni precisa sobre el número y tipo de libros que pudieron leer los voluntarios. Se sabe que el Patronato envió cerca de 700 volúmenes, pero nada sobre su perfil temático. Tampoco el testimonio de los combatientes ayuda a conocer qué leyeron. En muchas ocasiones su correspondencia se limita a indicar que han recibido un libro de poemas o una novela, sin ofrecer más pistas sobre títulos o autores. El registro de Solé i Pla, pese a ser incompleto, arroja algo de luz sobre este punto. Su documentación solo identifica 579 ejemplares correspondientes a 53 obras, aunque existen suficientes indicios para afirmar que el número de libros distribuidos por el Comitè rondaría los 2.000.

A diferencia de los servicios de lectura de los países beligerantes, la selección de los libros enviados por el Patronato y el Comitè no compartió la lógica impuesta por las autoridades militares: no buscó fortalecer la moral combativa, ni avivar el espíritu de sacrificio, ni tampoco instruir técnicamente a las tropas. Al tratarse de dos iniciativas prácticamente individuales, la impronta de sus promotores quedó reflejada en el material elegido.

En el caso del Comitè, sus envíos tradujeron las afinidades personales, la filiación ideológica y, probablemente, los gustos literarios de Solé i Pla. Las obras remitidas por el Comitè compartieron además dos características: la primera es su contemporaneidad; en su inmensa mayoría fueron textos publicados en los años previos al estallido de la guerra. El más antiguo data de 1886, y nueve de los 53 títulos de los que se tiene constancia vieron la luz durante el conflicto. La segunda tiene que ver 
con la procedencia de los autores; todos ellos catalanes, incluyendo en este grupo a los escritores roselloneses, con la sola excepción de una pieza teatral de Turgueniev traducida por Narcís Oller. Si a ello se añade que en su mayoría se trató de textos literarios, se puede deducir que su objetivo principal fue distraer y mantener vivo el recuerdo de la patria a través de la lectura en la propia lengua.

Aunque hubo textos poéticos, el grueso de los envíos correspondió a la narrativa, mientras que lo que podría considerarse como ensayos se redujo a las obras del jurista e historiador Josep Pella i Forgas (Llibertats y antich govern de Catalunya), a las del periodista y político Antoni Rovira i Virgili (Història dels moviments nacionalistes) y las de su amigo, el articulista y corresponsal Eugeni Xammar, quien desde Londres publicó sin firmar varios opúsculos contra la prepotencia germánica; dos de ellos, Contra la idea d'imperi y Pel camí dret, pel camí tort, engrosaron la biblioteca del foyer de Valbonne. A través de los textos de estos tres autores se intentó alimentar el ideario de aquellos combatientes que creían contribuir con su lucha al futuro reconocimiento internacional de Cataluña.

Una revisión de los autores de las 53 obras de las que se tiene noticia que distribuyó el Comitè permite agruparlas en cuatro categorías.

- Obras de autores comprometidos con la causa aliada y que escribieron sobre la guerra o para los combatientes. En este grupo destacan Alfons Maseres, miembro del Comitè de Germanor, y de quien se distribuyeron dos títulos: la antología Contes fatídics y, especialmente, el relato breve Memòries d'un voluntari; Carles Grandó, y Francis i Ayrol, autores respectivamente de Clam roig y Les hores que passen, dos poemarios dedicados a los voluntarios; Pere Ferrés-Costa, soldado caído en 1915 y cuya obra póstuma, Proeses d'amor $i$ patriotisme, circuló entre los combatientes siendo muy admirada; finalmente cabría incluir a Eugeni Xammar, Antoni Rovira i Virgili y Josep Vives i Borrell.

- Obras de autores con los que Solé i Pla mantuvo una estrecha relación. Sin duda, el mejor ejemplo es el del periodista Pere Aldavert, amigo inseparable del presidente del Comitè. Una amistad iniciada en la defensa de un ideario político común y consolidada durante la guerra. No parece casual que de ningún otro autor se enviasen tantos títulos, en concreto ocho antologías de crónicas y notas sobre la actualidad política y social catalana, aunque ninguna de ellas fue publicada después de 1907: A la taleya, A salt de mata, Cantant y fent la meva, D'altres temps, Encara són de moda, Feina nova, Per la dotzena, y Per no desdir.

- Obras de figuras de la Renaixença y el Modernismo catalanes. Por el número de títulos destacan Narcís Oller y Jacint Verdaguer. Del primero, se tiene noticia del envío de ejemplares de cuatros obras: tres colecciones de relatos y la novela Pilar Prim. Del segundo, tres títulos: Viatges, una antología de prosas, y ejemplares de los poemarios Patria y Canigó. De la recepción de este último existe el testimonio de Manuel Fernández. El libro llegó a sus manos en lugar de la gramática catalana que había solicitado a Solé i Pla "per aprendre a 
escriure un poc bé en català" ${ }^{28}$, pero pronto agradeció el valor de aquel monumento literario al descubrir que "amb aquests poemes trobaré paraules de tota la gramática catalana i podré guiar-me per escriure" 29 . Además de las obras de Oller y Verdaguer, en esta categoría se deben incluir Horacianes, el poemario más conocido de Miquel Costa i Llobera; La dona mediterrània de Pompeu Gener; D'aquí $i$ d'allà de Santiago Rusiñol, y textos de otros modernistas, como Jaume Massó i Torrents y Joan Pons i Massaveu.

- Por último, cabe referirse a un conjunto de obras de autores heterogéneos. Un cajón de sastre que bien podría responder a los gustos personales de Solé i Pla, o la coyuntura editorial. En la nómina de los autores de esta categoría se encuentran novelistas como Josep Morató i Grau, Carles de Fortuny, Miquel Roger i Crosa y el poeta Josep Burgas.

El número de ejemplares distribuidos de los títulos documentados fue muy desigual. A ello pudieron contribuir su precio y disponibilidad pero, por encima de todo, su contenido y oportunidad. No en vano, las obras más distribuidas fueron las que se escribieron pensando en los combatientes o intentando reflejar su cotidianidad, como la novela corta Memòries d'un voluntari de Alfons Maseras, de la que se enviaron al frente 400 ejemplares, o los libros de poemas Les hores que passen de Francis i Ayrol y Clam roig de Carles Grandó, de los que, en conjunto, se remitieron casi un centenar de copias.

\section{Conclusiones}

La neutralidad durante la Primera Guerra Mundial no impidió que en España aparecieran iniciativas para proporcionar auxilio material a los soldados. El envío de lectura fue una más de las acciones con las que se ayudó a los combatientes. A pesar de ser iniciativas modestas, no constituyeron un hecho aislado, sino en completa sintonía con la movilización de libros y prensa sin precedentes que se produjo durante la guerra. Todas las grandes potencias en contienda organizaron servicios de lectura con los que atender a sus tropas en cualquiera de los escenarios del conflicto.

Dejando al margen la obra desarrollada por la Oficina Pro Cautivos, dirigida a los prisioneros de guerra de ambos bandos, el resto de iniciativas españolas tuvo una dimensión humanitaria y solidaria pero, por encima de todo, ideológica. Si el compromiso de la campaña de Pere Coromines con la causa aliada fue inequívoco, la existencia de voluntarios españoles luchando del lado francés fue la razón de ser de la actividad desplegada en apoyo de aquel contingente por el Comitè y el Patronato. En consecuencia, parte del material de lectura que enviaron fue un reflejo del posicionamiento ideológico y político de ambas organizaciones.

Libros y publicaciones periódicas no se movilizaron por igual, y el protagonismo de la prensa no se debió solo al bajo coste que suponía su envío, sino a las funciones que tanto el Patronato como el Comitè le atribuyeron. Además de distraer, confortar 
o evadir, la prensa debía especialmente reforzar el vínculo con la patria mediante el seguimiento de su actualidad o el recuerdo de la lengua propia, y demostrar a los voluntarios la significación que su participación en la guerra tenía para ciertos sectores de la sociedad española. Sin embargo, en manos de sus destinatarios la prensa adquirió nuevos valores, fue un bien compartido entre compañeros, soporte moral, tribuna para la polémica, aparador del narcisismo de quienes día a día exponían la vida y reclamo para la ayuda de amigos y familiares.

La creación de una pequeña sección de libros para los voluntarios catalanes en la biblioteca del foyer de Vallbonne y la puesta en marcha de un periódico de trinchera demuestran que para una parte de aquel contingente, el más próximo al ideario del Comitè, leer fue indispensable para consolidar las convicciones por las que aquellos hombres habían decidido hacer suya aquella guerra.

\section{Referencias bibliográficas}

GONZÁLEZ QUESADA, A. (2011). "Soldados lectores: la movilización del libro durante la Gran Guerra". En: Zer: Revista de Estudios de Comunicación, n ${ }^{\circ}$ 16, vol. 30, Leioa: Universidad del País Vasco. p. 229-245.

(2014). "La otra evasión: libros y lectura para prisioneros durante la Primera Guerra Mundial". En: Hispania: Revista Española de Historia, n ${ }^{\circ} 247$, vol. LXXIV, Madrid: CSIC. p. 525-554.

IZQUIERDO, S. (2001). Pere Coromines. Barcelona: Afers.

MARTÍNEZ I FIOL, D. (1991). Els voluntaris catalans a la Gran Guerra (19141918). Barcelona: Publicaciones de l'Abadia de Montserrat.

MULlER, M. (2000). Les bibliothéques militaires dans le foyer du soldat. Paris: Université de Paris.

NELSON, R. L. (2010). "Soldier newspapers: a useful source in the social and cultural history on the First World War and Beyond". En: War in History, $\mathrm{n}^{\circ}$ 17(2), London: Sage. p. 167-191.

NATTER, W.G. (1999). Literature at war: 1914-1940: representing the 'Time of Greatness' in Germany. London: Yale University Press.

PANDO, J. (2002). Un rey para la esperanza: la España humanitaria de Alfonso XIII en la Gran Guerra, Madrid: Temas de Hoy.

PATRONATO DE VOLUNTARIOS ESPAÑOLES. (1920). Memoria de su situación, 1918-1919. Madrid: Comité de Aproximación Franco-Española.

SUBIRÁ, J. (1920). Memorias y diarios: recopilación glosada. Madrid: Patronato de Voluntarios Españoles.

(1922). Epistolarios y narraciones: selección refundida. Madrid: Patronato de Voluntarios Españoles.

YOUNG, A. (1981). Books for sammies. Pittsburgh: Beta Phi Mu. 


\section{Notas}

1 "Por los mil de Cataluña". Iberia, 13 de febrero 1916, p. 5.

2 Carta de Emilio Ma de Torres a Luis Polo de Bernabé, 6 de febrero de 1917, Alfonso XIII (Oficina pro cautivos) AGP, legajo 671.

3 Llibre de comptes, (Fons Solé i Pla), Arxiu Nacional de Catalunya.

4 PATRONATO DE VOLUNTARIOS ESPAÑOLES. Memoria de su situación, 1918-1919.

5 Freixes, Miquel, 17 abril 1916. Lletres de combatents. Vol. E-F. (Fons Solé i Pla)

6 Campanyà, Camil, 27 febrero 1916. Lletres de combatents. Vol. C-D. (Fons Solé i Pla)

7 "Por los voluntarios catalanes de Francia”. Iberia, 24 junio 1916, p. 11

8 Nat, Angel, 27 febrero 1915. Lletres de combatents. Vol. L-N. (Fons Solé i Pla)

9 Martínez, Angel, 24 abril 1916. Lletres de combatents. Vol. L-N. (Fons Solé i Pla)

10 Casalta, Ernest, 18 marzo 1917. Lletres de combatents. Vol. C-D. (Fons Solé i Pla)

11 "los diarios que con la otra carta dice que no nos ha enviado no los hemos recibido todavía; pero no tenga miedo, no se perderán, si fueran longanizas se perderían”. Llensa, Pere, 19 noviembre 1917. Lletres de combatents. Vol. L-N. (Fons Solé i Pla)

12 Palé, Ferriol, 28 noviembre 1916. Lletres de combatents. Vol. N-P. (Fons Solé i Pla)

13 Fernández, Manuel, 13 noviembre 1917. Lletres de combatents. Vol. E-F. (Fons Solé i Pla)

14 Pou, Jaume, 6 junio 1917. Lletres de combatents. Vol. N-P. (Fons Solé i Pla)

15 "No todo el mundo sirve para ir al frente, es verdad, pero los hay que no podrán pasar una noche larga y fría llena de angustia con el fusil o la bomba en la mano, pero en cambio, esos son capaces de tener una pluma en la mano y escribir palabras alentadoras para aquellos que luchan en la trinchera, esos que no son buenos para ir al frente, y que escriben y hablan tan bien, algún día cuando la hora de la justicia llegue, ellos con sus elocuentes palabras sabrán reclamar y defender la causa que todos, unos y otros defendemos: unos con el fusil y otros con la pluma, entonces, éstos son unos héroes, tanto o más que nosotros". Pou, Jaume, Carta, 12 noviembre 1916. Lletres de combatents. Vol. N-P. (Fons Solé i Pla)

16 García, Enric, 30 enero 1918. Lletres de combatents. Vol. G-K. (Fons Solé i Pla)

17 Pou, Jaume, 25 octubre 1916. Lletres de combatents. Vol. N-P. (Fons Solé i Pla)

18 Bernabé, Francesc, 17 julio 1918. Lletres de combatents. Vol. B. (Fons Solé i Pla)

19 “ Torelló, Josep, 15 julio 1917. Lletres de combatents. Vol. T-V. (Fons Solé i Pla)

20 "Me gustaría mucho que hiciese todo lo posible para encontrarlo, porque será el único recuerdo de la Legión Extranjera que podría guardar". García, Enric, 30 enero 1918. Lletres de combatents. Vol. G-K. (Fons Solé i Pla)

21 "cada día los abusos serían más grandes y entonces el diario acabaría por perder la reputación”. Bastús, Joan, 15 febrero 1917. Lletres de combatents. Vol. B. (Fons Solé i Pla) 
22 "si no tiene inconveniente de enviarnos algunos diarios catalanes para poder pasar unos momentos distraídos y recordar los tiempos que pasábamos en aquella tierra catalana". Barceló, Alfred, 21 mayo 1916. Lletres de combatents. Vol. B. (Fons Solé i Pla)

23 Subirá, J. Memorias y diarios, p. 67

24 Bastús, Joan, 30 julio 1916. Lletres de combatents. Vol. B. (Fons Solé i Pla)

25 "no puede imaginarse con la alegría que los hemos leído, a pesar de haberlos leído y releído los guardo como si dentro de los artículos que encajan se encontrasen pedazos de todas aquellas cosas tan gratas que todo hombre alejado de su patria quiere por encima de todas las riquezas y placeres del mundo". Serrat i Casas, 7 marzo 1917. Lletres de combatents. Vol. P-S. (Fons Solé i Pla)

26 “(...) ateneo donde se daban conferencias serias, o que querían serlo y con la intención ya era suficiente, donde se hacían controversias a veces largas que duraban horas (...)". Solé i Pla, Joan. [La Gran Guerra: notes personals], fol. 117 (Fons Solé i Pla)

27 "se encontraban entonces en falta por culpa de su poca cultura histórica. En la escuela no se les había enseñado nada más que el abecé y las cuatro reglas". Ibid. 120.

28 Fernández, Manuel, 12 junio 1916. Lletres de combatents. Vol. E-F. (Fons Solé i Pla)

29 “con estos poemas encontraré palabras de todas la gramática catalana y podré guiarme para escribir". Fernández, Manuel, 14 septiembre 1916. Lletres de combatents. Vol. E-F. (Fons Solé i Pla).

\section{El autor}

Doctor en Ciencias de la Información, licenciado en Filología Catalana, diplomado en Biblioteconomía y Documentación. Profesor titular del Area de Documentación de la Universitat Autònoma de Barcelona. Miembro del GRP (Grupo de Investigación en Publicidad). Ha publicado diversos trabajos sobre la organización de los servicios de lectura durante la Primera Guerra Mundial. 